\title{
Nuclear Behaviour and Ascospore Delimitation in Xylosphaera polymorpha
}

\author{
By A. BECKETT AND R. M. CRAWFORD \\ Department of Botany, University of Bristol, Bristol, BS8 IUG
}

(Accepted for publication 3 August 1970)

\begin{abstract}
SUMMARY
Nuclear behaviour and ascospore delimitation in Xylosphaera polymorpha was studied by light and electron microscopy. Electron-dense bodies occurred near nuclei at all stages from crozier formation to the development of young ascospores. It is suggested that these bodies be termed archontosomes. Ascospores were delimited by the invagination of an ascus vesicle and the archontosome-astral-ray complex participated in both the delimitation and orientation of the ascospores. The possible role of this complex in determining ascospore form is discussed.
\end{abstract}

\section{INTRODUCTION}

The cytology of the ascus has been extensively studied with the light microscope but comparatively few investigations have been made with the electron microscope. The presence of nuclear beaks and astral-ray-'centrosome' complexes and their participation in ascospore delimitation was first reported by Harper (1897). He suggested that the delimiting membranes were formed by the lateral and end-to-end fusion of the astral rays which curved around the nuclei. Some of Harper's claims have been refuted and other mechanisms of ascospore delimitation suggested (Beckett, I966; Carroll, 1966; Reeves, 1967). Recent observations with the electron microscope on sections of potassium permanganate-fixed material have shown that in several genera of Discomycetes ascospores are delimited by the invagination around individual nuclei of an ascus vesicle composed of two unit membranes (Bracker, I967; Carroll, 1967; Reeves, I967; Oso, I969). Schrantz (I967) confirmed the presence of nuclear beaks, 'centriolar plaques' and astral rays in formaldehyde-fixed preparations of the Discomycete Pustularia cupularis. He concluded that the spores were delimited by a vesicle formed from endoplasmic reticulum rather than by the fusion of astral-ray microtubules, but otherwise Schrantz made no reference to the possible role of the 'centriolar plaques' and astral rays during spore delimitation. Carroll (1966) suggested that the astral rays around the nuclei might act as physical barriers to the infolding delimiting membranes. Bracker (1967) suggested that astral rays might direct the pattern of invagination by pulling in the vesicle membrane from the ascus periphery. The present paper reports on the behaviour and function of these various structures during ascus development and spore delimitation in the Pyrenomycete fungus Xylosphaera polymorpha (Persoon ex Merat) Dumortier (=Xylaria polymorpha) and attempts to resolve some of the confusion about the terminology of these organelles. 


\section{Light microscopy}

\section{METHODS}

Stromata which contained perithecia of various ages were cut into thin slices, immersed in $\mathrm{I}: 3(\mathrm{v} / \mathrm{v})$ propionic acid:ethanol solution, and fixed as described by Beckett \& Wilson (I968). The slices were then placed in $70 \%$ ethanol for $20 \mathrm{~min}$., rinsed briefly in distilled water, hydrolysed in $\mathrm{IN}-\mathrm{HCl}$ at $60^{\circ}$ for 3 to $7 \mathrm{~min}$., washed in several changes of distilled water and finally stained in propiono-carmine (Beckett \& Wilson, 1968). Preparations were viewed and photographs taken with a Zeiss photomicroscope.

\section{Electron microscopy}

Stromata were cut into slices while immersed in cold fixative. The fixative used was a mixture of equal volumes of $3 \%$ glutaraldehyde and $3 \%$ acrolein both in $\mathrm{O} \cdot \mathrm{I} \mathrm{M}$ sodium cacodylate buffer with sucrose added (final molarity of 0.3 ), and a final pH of 7.0. Material was fixed for 20 to $60 \mathrm{~min}$., the first $10 \mathrm{~min}$. being under vacuum, washed in several changes of buffer, post-fixed in $2 \%$ osmium tetroxide in 0.1 Msodium cacodylate buffer, $\mathrm{pH} 7 \cdot 0$, at $4^{\circ}$ for $\mathrm{I} 2$ to $16 \mathrm{~h}$., washed again in buffer, dehydrated in a graded ethanol/water series, soaked in propylene oxide and embedded in Epon. Sections were cut on an LKB ultramicrotome, stained with uranyl acetate followed by lead citrate (Reynolds, I963) and viewed with an AEI EM6B electron microscope.

\section{RESULTS}

\section{Light microscopy}

Amorphous structures were seen near the pre-fusion nuclei in the ascogenous hyphae and croziers (Pl. I, fig. I, arrows). These structures, which will be called archontosomes, stained less densely than did the nuclei, and one archontosome was associated with each nucleus. After karyogamy the ascus elongated and the fusion nucleus entered meiotic prophase. During pachytene and diplotene the elongated, paired chromosomes became spread out within a large elongated (c. 8 to Io $\mu \mathrm{m}$.) nucleus. There was also a corresponding division and migration of the archontosomes resulting in the appearance of one at either end of the nucleus (Pl. I, fig. 2, arrows). Archontosomes viewed with the light microscope closely resembled the 'centrosomes', or 'centriolar plaques', found in many Ascomycetes (e.g. Singleton, 1953; Carr \& Olive, 1958; Robinow \& Marak, I966; Lu, I967; Beckett \& Wilson, I968). One edge of the archontosome often appeared to be more heavily stained than the rest (P1. I, fig. 2, top arrow).

Metaphase I was characterized by the presence of a longitudinal spindle, the poles of which were located at the densely stained, rod-like archontosomes (Pl. I, fig. 3). Both archontosomes appeared to be orientated transversely with respect to the spindle and the ascus, and their lightly stained, amorphous parts were not visible at this stage. During anaphase I (Pl. I, fig. 4) there was an indication of the presence of astral rays radiating from the vicinity of the upper archontosome (P1. I, fig. 4, arrow). Archontosomes were seen at all stages of divisions II and III in the ascus and were identical with those described above.

Each interphase nucleus at the end of division III possessed a single archontosome 
situated beneath the nucleus at the tip of the so-called nuclear beak (Pl. I, fig. 5). In Pl. I, fig. 5 the rod-like archontosome is readily seen in the upper two nuclei. Sometimes asci were seen in which the eight nuclei were disposed in a biseriate arrangement (PI. I, fig. 6). No delimiting membranes were detected at this stage with the light microscope. Two features (Pl. I, fig. 7) caused newly delimited spores to be visible with the light microscope: a thin, dense line around each nucleus and a densely stained rod-like structure 2.5 to $3 \mu \mathrm{m}$. long, pointing towards the base of the ascus and extending between the nucleus and the enclosing membrane(s). Later, the outline of the young spores was distinct, the rod-like structure no longer visible and a dense curved archontosome apparent at the base of some of the spores (Pl. I, fig. 8, arrows).

\section{Electron microscopy}

Sections through the very young crozier cell showed the pre-fusion nuclei lying side by side, each associated with a single electron-dense amorphous archontosome about $\mathrm{I} \cdot 4$ to $\mathrm{I} \cdot 6 \mu \mathrm{m}$. long (P1. 2, fig. 9). At this stage there was no evidence of a differentiation of the nuclear membrane adjacent to the archontosome. The ensuing diploid nucleus was associated with a similar archontosome (PI. 2, fig. I0), and in some young asci at this stage microtubules were seen between the archontosomal material and the nuclear envelope (Pl. 2, fig. II).

As expected from light microscopy the meiotic prophase nucleus was elongated parallel to the long axis of the ascus. At pachytene dense synaptinemal complexes occurred (Pl. 2, fig. I2; Pl. 3, fig. I4), the archontosome region often extended for a considerable distance around the nuclear envelope (Pl. 2, fig. 12), and the nuclear membrane adjacent to the archontosome material was differentiated from that elsewhere by an increase in density (Pl. 2, fig. I2, arrows). Large blebs, or blow-outs, of the nuclear envelope were also characteristic of the prophase fusion nucleus. A deposit of electron-dense material was associated with well-developed blebs, around and along the membrane surrounding them (Pl. 2, fig. 13). Strands of endoplasmic reticulum were sometimes seen lying close to a nuclear bleb. At anaphase I the nucleus was irregularly lobed and the poles of the intranuclear spindle were occupied by an archontosome which then appeared as an electron-dense band of material situated within a characteristic indentation of the nuclear membrane (Pl. 3, fig. I5, I6). Spindle microtubules extended through the nucleoplasm to the chromosomes. Plate 3 , fig. I6 shows at least three separate tubules ending at what is apparently a 'ball-and-socket type' kinetochore embedded within a chromosome. Longitudinal sections of astral-ray microtubules can be seen radiating into the ascus cytoplasm on the outside of the archontosome.

No signs of the formation of an ascus vesicle were seen either at this stage or at anaphase II (PI. 3, fig. I7). At all of the three divisions in the ascus the archontosomes were closely associated with astral-ray microtubules, but at division III these microtubules appeared to be developed to a greater extent (Pl. 3, fig. I8). In some sections large bands of ray microtubules about 3 to $4 \mu \mathrm{m}$. long were seen in the ascus cytoplasm. A frequent feature at metaphase III, and illustrated in Pl. 3, fig. I8, was the asymmetrical location of the spindle and metaphase plate with respect to the centre of the nucleus. This asymmetry resulted in a very short spindle, the length of which was almost entirely occupied by the chromosomes. During nuclear division III an ascus vesicle was assembled at the periphery of the ascus. Both nuclear division and 
development of this vesicle appeared to proceed in a basipetal sequence. Plate 3 , fig. I 8 shows a longitudinal section through the apical nucleus of a tetranucleate ascus. Part of the ascus vesicle can be seen on the left immediately inside the plasmalemma, but there was no sign of the vesicle membrane immediately below this region of the ascus. The three lower nuclei in the ascus had yet to enter metaphase of division III.

Plate 4, fig. I9 shows a longitudinal section through another tetranucleate ascus in the region of the two lower nuclei, which appear to be still at interphase following division $\Pi$. In the basal nucleus of this pair seen in another section (Pl. 4, fig. 20), nuclear blebs were seen separated from the nuclear envelope as well as in a very early stage of formation from it (arrows). Large amounts of endoplasmic reticulum were nearby though assembly of the ascus vesicle membranes had not yet begun. In section the ascus vesicle membranes showed the typical tripartite unit membrane configuration with an asymmetry caused by the inner dense layers of each membrane being thicker than the outer ones (Pl. 4, fig. 2I). A narrow band of electron-dense material lined the outer surface of each membrane. Plate 4 , fig. 22 shows a tangential longitudinal section of an early stage in the envelopment of nuclei by the ascus vesicle. Astral-ray microtubules in both longitudinal and transverse section show in the cytoplasm. They extend towards the vesicle membranes, which in the upper part of the micrograph have invaginated from the periphery towards the centre of the ascus. In a median longitudinal section ( $\mathrm{Pl} .4$, fig. 23) the nuclear beak can be seen and the archontosome appears as a curved bar of electron-dense material outside the tip of the beak. The archontosome and its astral-ray microtubules lie at the base of the young spore initial, i.e. pointing towards the base of the ascus.

A conspicuous feature at this stage is the electron-dense material surrounding each astral-ray microtubule (Pl. 4, fig. 23; Pl. 5, fig. 24, 25, 26, 27). A longitudinal section through part of an ascus at an early stage in spore delimitation is seen in Pl. 5, fig. 24. In two of the spore initials the archontosome-astral-ray complex can be seen on the upper side of the nucleus, while in the other two the astral rays are seen in cross section on the lower side of each nucleus. Another section of the same ascus (Pl. 5, fig. 25) shows two apparently delimited spores with astral rays near the base of each. Plate 5, fig. 26 , shows a longitudinal section through part of an ascus at a later stage when the young spores were fully delimited. The archontosome-astral-ray complex shows at the base of each spore. Since each archontosome was associated with the nuclear beak, clearly seen in the upper two spores, this arrangement resulted in a distinct orientation of both the nucleus and the spore. In many asci the delimited spores were biseriate and the archontosomes then lay side by side at the bases of adjacent spores ( $\mathrm{Pl}$. 5, fig. 27). The fibre body, seen within the nucleus of the young spore in Pl. 5, fig. 27, was a common feature. Details of its structure and possible function will be reported elsewhere.

Soon after their delimitation the spores elongated and wall material was laid down between the two membranes, of which the inner formed the plasmalemma of the spore and the outer the investing spore membrane (Pl. 6, fig. 28, 29). At this stage in spore development the base of each spore became characteristically rounded and slightly bulbous as seen in longitudinal section. Within the base an electron-dense archontosome then lay beneath the nucleus and approximately 2 to $5 \mu \mathrm{m}$. from it depending on the degree of spore elongation. Numerous microtubules ran through the spore cytoplasm from the archontosome towards and to the side of the nucleus. These sometimes 
measured 3 to $4 \mu \mathrm{m}$. in one plane of section. Neither the archontosome nor the microtubules appeared to be connected to the nuclear membrane and there was no sign of the differentiated indentation of the nuclear envelope at the lower end of the nucleus. An archontosome was, however, apparent towards the upper end of the nucleus (P1. 6, fig. 28 , arrow), but no microtubules were present at this point.

\section{DISCUSSION}

\section{Archontosomes}

The term archontosome (Greek, meaning 'organizing' or 'controlling body') is proposed for the following structures: (I) the amorphous, electron-dense structure situated near to each nucleus in the young crozier; (2) the amorphous structure associated with the differentiated nuclear envelope at meiotic prophase; (3) the rod-like body, lying in an indentation of the nuclear envelope, which is located at the pole of the spindle at metaphase and anaphase of all nuclear divisions; (4) the curved bar of dense material which lies near the nuclear beak at interphase III and during spore delimitation; (5) the electron-dense structure associated with a band of microtubules at the base of the developing spore.

Our light and electron micrographs establish that all these 'structures' are the same organelle.

There is considerable confusion regarding the terminology of this organelle in Ascomycetes and Basidiomycetes, because the terms used ('centriole', 'centriolar plaque' and 'centrosome') are ones which by definition relate to a body or organelle with a precise structure and function at a specific time in the nuclear cycle of the cell. Went (I966) showed that centrioles and centrosomes could be defined on the basis of their structure and function. Electron-microscope studies have shown that from a structural aspect the term centriole should be used for the tubular organelle composed of a ring of nine triplet microtubules which are radially tilted in a clockwise direction when viewed from the proximal end. On a functional basis the centriole is the polarizing body of the mitotic spindle in aquatic Phycomycetes, and also constitutes at least part of the kinetosome at the base of the flagella in the motile stages of these fungi. Cleveland (1963) appears to consider the term centriole valid for any organelle which forms the achromatic figure (astral-ray-spindle complex), irrespective of its structure. Structurally, a centriole has never been convincingly demonstrated in either the Ascomycetes or Basidiomycetes. The report of a so-called central body in yeast cells by Lindegren, Bang \& Osmui (I965) is not conclusive. The association of centrioles with flagella cannot be demonstrated in Ascomycetes or Basidiomycetes since they have no flagellate stages. It seems therefore that the only basis for suggesting that a centriole occurs in the higher fungi is that there is a structure situated at the poles of the spindle during nuclear division in these fungi.

The term centriolar plaque was first used by Robinow \& Marak (1966) to describe the bipartite, electron-dense, structure situated within an invagination of the nuclear envelope at the poles of the intranuclear fibre apparatus in Saccharomyces. This is an unfortunate term both with Saccharomyces and with Xylosphaera since the structure is neither associated with a flagellum nor of 'centriolar' form. In addition, in Xylosphaera it is strictly a plaque only when constituting the poles of the spindle at metaphase and anaphase of nuclear division. 
Centrosomes have been known (Cleveland, 1963) since the studies of Boveri on animal cells. He defined these organelles as large hyaline bodies situated at the poles of the mitotic spindle. In I90I Boveri (cited in Cleveland, 1963) redefined centrosomes as hyaline bodies which surround the smaller, deeply staining centriole(s), and modern definitions generally adhere to this later usage (De Robertis, Nowinski \& Saez, I965; Brown \& Bertke, 1969).

Both light and electron microscopy reveal in Ascomycetes an amorphous body associated with the nucleus in the croziers and in the developing ascus. When stained, this body is dense and does not contain a centriole at its centre. It does, however, replicate and appears to be intimately involved with the organization of both astral-ray and spindle microtubules and further plays a part in ascospore delimitation and development. Cleveland (1963) states that the centrosome plays no part whatever in the production of the achromatic figure or of any other organelle and is not autonomous. He also states that the centrosome is produced anew by the centriole in each cell generation. If one accepts that centrioles do not exist in Ascomycetes and Basidiomycetes, it is unlikely that a centrosome could occur in their absence.

It is suggested that the dense body found near nuclei in Xylosphaera is not adequately described by any of the above terms, and that a more suitable one is required for this organelle in Ascomycetes and if necessary in Basidiomycetes. It is suggested that the term archontosome be adopted. It is defined as an amorphous, electron-dense body near the nucleus which is associated with the astral-ray and spindle microtubules and later the microtubules concerned with spore delimitation and development. At some stages in the cell it resembles the centriolar plaque (sensu Robinow \& Marak, I966) in both form and behaviour and performs the function of a centriole during nuclear division. However, at no stage does the archontosome possess the structure of a centriole. The development and behaviour of the archontosome in Xylosphaera is summarized in Fig. I.

Differences in the shape of this organelle have been reported for numerous Pyrenomycete fungi (Colson, I934; Singleton, I953; Heslot, 1958; Carr \& Olive, I958; Lu, I967) and have usually been regarded as characteristic for the different genera concerned. Beckett \& Wilson (I968) showed that the 'centrosome' in Podospora anserina was seen with the light microscope as a disc at division I, a rod at divisions II and III, and as a plate at the nuclear beak and in spore-delimitation stages. The present work confirms the fact that the archontosome does indeed change its shape and further suggests that this is a sequential development linked with its role at the various stages in the cytology of the ascus (Fig. I). Carr \& Olive (1958) noted that one edge of the 'centrosome' in Sordaria fimicola was thick and deeply stained. They suggested that this edge represented the 'centriole' proper. Lu (1967) reported a similar dense edge on the 'centriole' in Gelasinospora calospora and proposed that this 'end-side' was the one associated with the spindle fibres. In Xylosphaera this asymmetry of the archontosome was seen with the electron microscope to result from its association with a differentiated region of the nuclear envelope, and it was at this point that staining was intense. Electron-microscope observations also confirmed that at metaphase and anaphase of meiosis and mitosis this region, which at these stages was plaque-like, was associated on one side with the spindle microtubules, and that astral ray microtubules lay near the outer side of it.

Heath \& Greenwood (1970) have shown that in Saprolegnia ferax the poles of the 
mitotic spindle are marked by the presence of a pair of true centrioles which lie in an indentation of differentiated nuclear envelope, termed a pocket by these authors. They showed that after division of the centrioles daughter pairs separated by migrating around the nuclear envelope, each pair being located within its pocket. Intranuclear spindle microtubules were formed from the inner side of each pocket. In Xylosphaera the centrioles were represented by the amorphous material of the archontosome which similarly became associated with the nuclear envelope, migrated around it and polarized the spindle. Doguet (I960) presented diagrammatically a similar behaviour pattern for the 'centrosome' in Sordaria fimicola.

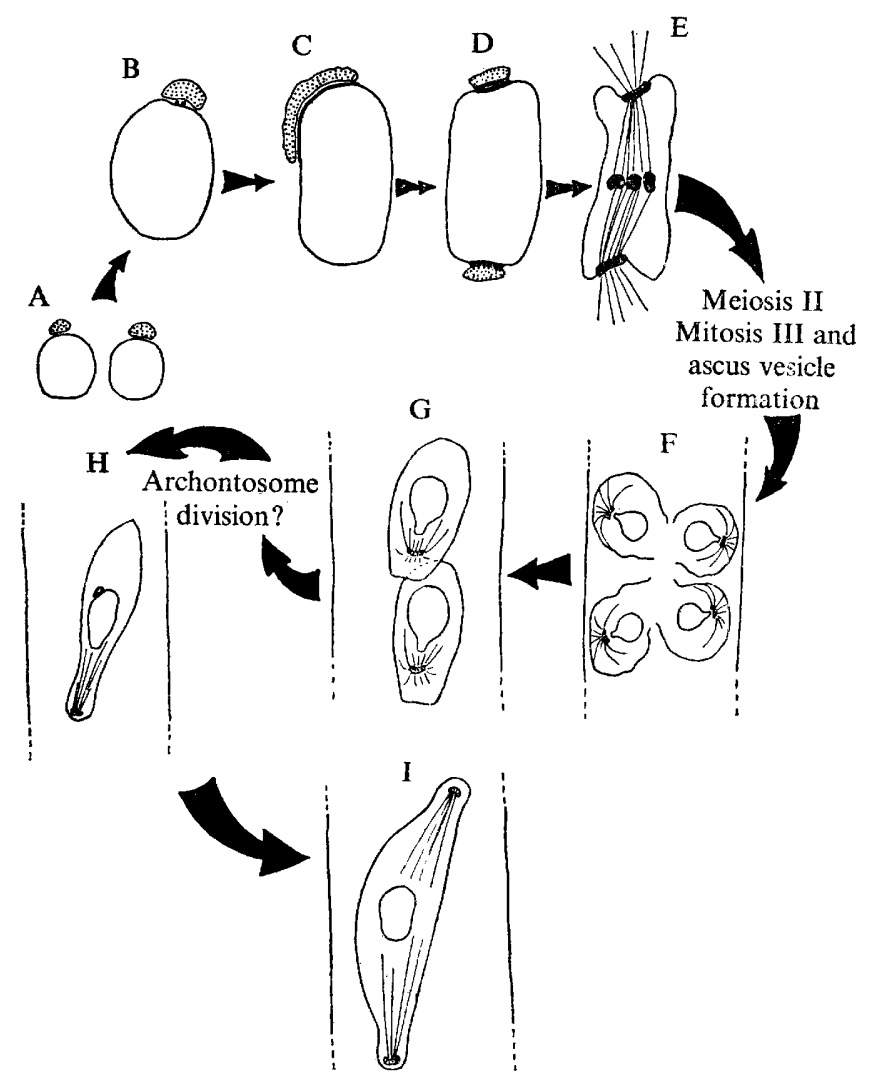

Fig. I. Semi-diagrammatic representation of the development and behaviour of archontosomes in Xylosphaera polymorpha. A, Pre-fusion nuclei with their associated archontosomes. $\mathrm{B}$, Fusion nucleus with one amorphous archontosome. Microtubules occur between the archontosome and the nuclear envelope. $\mathrm{C}$, Pachytene nucleus: migration of archontosome material around the differentiated nuclear envelope. D, Diplotene nucleus: division of the archontosome to form a distinct body at each end of the elongated nucleus. E, Metaphase I: plaque-like archontosomes located at the poles of the intranuclear spindle. Astral rays occur near the outside edge of the archontosomes. F, Ascospore delimitation by the inpulling of an ascus vesicle. $G$, Reorientation of archontosomes and astral rays within the spore initials. $\mathrm{H}$, Participation of archontosome and microtubules in determining ascospore form. I, Possible configuration of archontosomes and microtubules in the mature spore. 


\section{Astral rays}

Astral-ray microtubules occurred near the archontosome in Xylosphaera. The microtubules between the nuclear envelope and the archontosome in the young ascus before it elongated may have been at an early stage in their development. As the ascus developed, the number of astral rays and the size of the archontosome-astral-ray complex increased, reaching a maximum at metaphase-anaphase III and at spore delimitation. Similar observations were reported for Neurospora crassa (Singleton, I953) and Gelasinospora calospora (Lu, I967). It is likely that this reflects the increasing involvement of the complex with the initiation and organization of spore delimitation, an interpretation supported by the observation of Wells (1969) on the cytology of the ascus of Ascobolus stercorarius. When the astral-ray complex was fully developed, the microtubules were associated with a deposit of electron-dense material. This might have been an artefact caused by fixation at a low temperature, but Schrantz (1967) found similar material associated with astral rays in Pustularia cupularis, his micrographs showing the dense material to consist of granules not unlike ribosomes. Asymmetric spindles, as well as being frequent at metaphase III in Xylosphaera, are apparently common in Saprolegnia ferax (Heath \& Greenwood, 1970).

\section{Ascus vesicle}

The process of nuclear blebbing and ascus-vesicle formation in Xylosphaera confirms the original observations by Carroll (I966) on Saccobolus kerverni and Ascodesmis sphaerospora. The ascus vesicle in Xylosphaera did not appear to be assembled until the prophase III stage had been reached in the ascus, a later stage than that reported for vesicle formation in Pyronema domesticum (Reeves, 1967). The basipetal sequence of both ascus-vesicle assembly and nuclear division in Xylosphaera paralleled the sequence in spore maturation in other Pyrenomycete fungi (Beckett, I966). Bracker (1967) suggested that the ascus vesicle was formed by invagination of the plasmalemma of the ascus. High magnification electron microscopy of the vesicle membranes in Xylosphaera did not support this view. The plasmalemma in Xylosphaera was asymmetrical, the inner of the two osmiophilic layers being denser. An invagination of the plasmalemma would therefore have resulted in the denser of the two osmiophilic layers lying on the outside of the double membrane so formed and not on the inside, as our results showed. The problem of determining the precise origin of membrane systems is a difficult one, and is made more so by the apparent readiness with which membranes change their form according to function. It is possible that the membrane system which delimited ascopores might have been formed from the nuclear envelope, plasmalemma and endoplasmic reticulum, and that membranes from each source underwent changes to become ascus-vesicle membranes.

\section{The delimitation process}

The involvement of 'centrioles' in ascospore delimitation has been reported by a number of workers but the precise mechanism is uncertain. In Xylosphaera the astral-ray microtubules acted as links between the ascus vesicle and the archontosomes. If these microtubules contracted or depolymerized at the archontosome in much the same way as certain spindle microtubules appear to depolymerize at the spindle pole, 
the result might be a pulling in of the vesicle at points coinciding with the nuclei since the archontosomes were at this stage intimately associated with the nuclear beak. This would be consistent with the mechanism suggested by Bracker (1967). The curving of astral-ray microtubules around the nuclei might also have controlled the initial path of invagination and ensured the inclusion of each nucleus within a spore initial.

Correlation of light and electron microscope observations is difficult due to the low resolution of the light microscope and its inability to resolve the membranes at early stages of ascospore delimitation. In Xylosphaera the nuclear-beak stage (Pl. I, fig. $5,6)$ probably represented a stage at which the archontosome-astral-ray complex had undergone reorientation within spore initials which had already been delimited by the double membrane system and was equivalent to the stages shown in Pl. 4, fig. 23; P1. 5, fig. 26, 27. Reorientation of the archontosome-microtubules complex at the base of young spores is understandable in view of its participation in determining ascospore shape. Several light microscopists have claimed that 'centriole'-astral-ray complexes do not exist and that spore delimitation occurs by autonomous cleavage of the ascus cytoplasm. This interpretation may be due to the apparent absence of 'centriole'-astral-ray complexes from unsuitably stained material, or, as suggested by Reeves (1967), ascospores may already have been delimited at the time of observation.

\section{Ascospore shape}

The densely stained band of material seen with the light microscope in ascospores at the stage at which the spore outline became detectable (Pl. I, fig. 7) could be seen with the electron microscope to consist of a number of microtubules. These microtubules (c. 3 to $5 \mu \mathrm{m}$. in length) were closely associated with an archontosome at the base of the spore and extended from it past the lower end of the nucleus. Spores at this stage had elongated considerably to approximately Io to I I $\mu \mathrm{m}$. and the nuclei occupied the middle portions. This system of microtubules may have played a part in shaping the spore. The synthesis or polymerization of sub-units to form microtubules at the archontosome might conceivably have pushed the base of the spore initial outwards. Such a mechanism would, however, have required the microtubules either to have been anchored at their upper ends or to have continued right through the spore to the tip. This has not been confirmed but microtubules have been seen to pass on either side of the nucleus. In the related fungus Rosellinia aquila microtubules extend for a considerable distance past the nucleus (Beckett \& Crawford, unpublished). It is not known whether these microtubules exist merely by persistence of the astral-ray microtubules from an earlier stage in development or whether they are formed anew. The absence of electron-dense material normally associated with astral-ray microtubules is, however, notable.

Sections showing a microtubule system at the apex of the spore have not been obtained, but a slightly constricted projection of the spore similar to that seen at the base of the spore (PI. 6, fig. 28) is known to occur at a later stage of development. It is possible that the archontosome seen associated with the nuclear envelope on the upper end of the nucleus (Pl. 6, fig. 28) might later have been involved in shaping the apical region of the spore. A similar role was implied by Wells (I956) for what she termed the centriole in ascospores of Sporormia obliquisepta. Jones (I926) and Jenkins (I934) noted the sudden appearance of the 'centriole' at one end of the spore initial in 
Ophiobolus graminis and Cordyceps agariciformia respectively, both of which form filiform ascospores. It now seems likely that here also spore shape is determined by a microtubule-archontosome complex.

The authors wish to thank Professor L. E. Hawker, Dr M. F. Madelin and Dr R. Campbell for their helpful advice and discussion during the preparation of this paper. Thanks are also due to Mr M. R. Curnock for technical assistance.

\section{REFERENCES}

BECKETT, A. (1966). Observation on the structure of hyphae, asci and ascospores, with special reference to Pleurage anserina, using light, phase contrast and electron microscope techniques. Ph.D. Thesis, University College of Wales, Aberystwyth.

BecketT, A. \& Wilson, I. M. (1968). Ascus cytology of Podospora anserina. Journal of General Microbiology 53, 8I-87.

BRACKER, C. E. (1967). Ultrastructure of fungi. Annual Review of Phytopathology 5, 343-374.

Brown, W. V. \& Bertke, E. M. (1969). Textbook of Cytology, p. 565. St Louis: Mosby.

CARr, A. J. H. \& Olive, L. S. (I958). Genetics of Sordaria fimicola. II. Cytology. American Journal of Botany 45, I42-I5O.

CARroll, G. C. (1966). A study of the fine structure of ascosporogenesis in Saccobolus kerverni and Ascodesmis sphaerospora. Ph.D. Thesis, University of Texas.

Carroll, G. C. (I967). The ultrastructure of ascospore delimitation in Saccobolus kerverni. Journal of Cell Biology 33, $218-224$.

Cleveland, L. R. (I963). Function of flagellate and other centrioles in cell reproduction. In The Cell in Mitosis, pp. 3-31. Edited by L. Levine. New York: Academic Press.

Colson, B. (1934). The cytology and morphology of Neurospora tetrasperma Dodge. Annals of Botany 48, 2 I I-224.

De Robertis, E. D. P., Nowinski, W. W. \& Saez, F. A. (1965). Cell Biology, p. 229. Philadelphia: Saunders.

Doguet, G. (1960). Contribution a l'étude du noyau du Sordaria fimicola. Revue de Cytologie et de Biologie Vegetale 22, $109-127$.

HARPER, R. A. (1897). Kerntheilung und freie Zellbildung im Ascus. Jahrbuch für Wissenschaftliche Botanik 30, 249-284.

Heath, I. B. \& Greenwood, A. D. (1970). Centriole replication and nuclear division in Saprolegnia. Journal of General Microbiology 62, I39-148.

Heslot, H. (1958). Contribution a l'étude cytogénétique et génétique des Sordariacées. Revue de Cytologie et de Biologie Vegetale 19, I-209.

Jenkins, W. A. (1934). The development of Cordyceps agariciformia. Mycologia 26, 220-243.

JoNes, S. G. (1926). The development of the perithecium of Ophiobolus graminis Sacc. Annals of Botany 40, 607-629.

Lindegren, G. C., BANG, Y. N. \& Osmu, M. (1965). The central body of the ascomycetes. Canadian Journal of Genetics and Cytology 7, 37-39.

LU, B. C. (1967). The course of meiosis and centriole behaviour during the ascus development of the ascomycete Gelasinospora calospora. Chromosoma, Berlin 22, 210-226.

Oso, B. A. (1969). Electron microscopy of ascus development in Ascobolus. Annals of Botany 33, 205-209.

ReEves, F. (1967). The fine structure of ascospore formation in Pyronema domesticum. Mycologia 59, I0I 8-1033.

REYNOLDS, E. S. (1963). The use of lead citrate at a high $\mathrm{pH}$ as an electron-opaque stain in electron microscopy. Journal of Cell Biology 17, 208-212.

Robinow, C. E. \& MARAK, J. (I966). A fibre apparatus in the nucleus of the yeast cell. Journal of Cell Biology 29, I 29-I 5 I.

Schrantz, J. P. (1967). Présence d'un aster au cours des mitoses de l'asque et de la formation des ascospores chez l'Ascomycète Pustularia cupularis (L.) Fuck. Compte Rendu Hebdomadaire des Séances de l'Académie des Sciences 264, 1274-1277. 
Singleton, J.R. (1953). Chromosome morphology and the chromosome cycle in the ascus of Neurospora crassa. American Journal of Botany 40, $124-144$.

WelLS, D. (1956). Nuclear changes accompanying ascus and ascospore development in Sporormia obliquisepta. American Journal of Botany 43, 76I-768.

Wells, K. (1969). Nuclear division in Ascomyetes. International Botanical Congress Ir, 235.

WENT, H. A. (1966). The behaviour of centrioles and the structure and formation of the achromatic figure. Protoplasmatologia VI G I, I-I09.

\section{EXPLANATION OF PLATES}

Key to lettering: $\mathrm{A}=$ archontosome, $\mathrm{AV}=$ ascus vesicle, $\mathrm{B}=$ bleb in nuclear envelope, $\mathrm{DM}=\mathrm{de}$ limiting membrane, $\mathrm{ER}=$ endoplasmic reticulum, $\mathrm{F}=$ fibre body, $\mathrm{K}=$ kinetochore, $\mathrm{MT}=$ microtubule(s), MTa = astral-ray microtubules, MTs = spindle microtubules, $\mathrm{N}=$ nucleus, $\mathrm{NB}=$ nuclear beak, $\mathrm{NE}=$ nuclear envelope, $\mathrm{SC}=$ synaptinemal complex.

\section{Plate 1}

Fig. I to 8. Light micrographs $(\times 2000)$ of Xylosphaera polymorpha.

Fig. 1. Crozier cells with pre-fusion nuclei and archontosomes (arrows).

Fig. 2. Meiotic nucleus at diplotene. Archontosomes are seen at the poles of the nucleus (arrows).

Fig. 3. Metaphase-anaphase I. Rod-like archontosomes are at the poles of the spindle.

Fig. 4. Late anaphase I. Radiating astral rays can be detected at the upper pole (arrow).

Fig. 5. Interphase III-ascospore delimitation. Archontosome-astral-ray complexes (arrows) can be seen at the bases of their respective nuclei. No membranes can be detected around the spores at this stage.

Fig. 6. Same stage as fig. 5 but with a biseriate arrangement of spores.

Fig. 7. Post-delimitation. Bands of dense material can be seen in the lower part of several spores (single arrows). The outline of the delimited spore can be determined (double arrow).

Fig. 8. A later stage in spore development. Densely stained archontosomes can be seen at the base of several spores (arrows).

\section{Plate 2}

Fig. 9. A section through part of a crozier cell. The pre-fusion nuclei can be seen with their associated archontosomes. $\times 10,000$.

Fig. Io. A section through a young ascus showing the fusion nucleus and one archontosome. $\times 12,000$. Fig. I I. Part of a young ascus. Four microtubules in cross-section lie between the archontosome and the nuclear envelope. $\times 46,000$.

Fig. 12. A longitudinal section through a meiotic nucleus at pachytene. The replication of the archontosome material, its association with, and presumed migration around, the nuclear envelope can be seen at the points marked by arrows. Synaptinemal complexes, in cross-section, are also seen. $\times$ I I ,250.

Fig. I 3. A section through part of a meiotic nucleus showing a well-developed nuclear bleb and what appears to be the initiation of a bleb (arrow). $\times 30,000$.

\section{Plate 3}

Fig. 14. A longitudinal section through a synaptinemal complex from a pachytene nucleus. $\times 30,000$.

Fig. 15. A longitudinal section through a nucleus at anaphase I. The upper end of the obliquely sectioned spindle is visible. $\times$ I0,000.

Fig. 16. Part of the spindle region of the nucleus shown in fig. 15. The archontosome is associated with an indentation of the nuclear envelope. Astral-ray and spindle microtubules are seen to the outside and inside of the archontosome respectively. $\times 30,000$.

Fig. 17. A longitudinal section through the upper nucleus at anaphase II. $\times$ I2,950.

Fig. I 8. A longitudinal section through the upper nucleus at metaphase III. The ascus vesicle is present to the left of the nucleus. $\times 12,950$. 


\section{Plate 4}

Fig. 19. A longitudinal section through part of an ascus in the region of the two lower nuclei at prophase III. Endoplasmic reticulum is abundant but no ascus vesicle can be seen. $\times 6000$.

Fig. 20. A serial section through the lower nucleus shown in fig. 19. One nuclear bleb has separated and another one is being formed (arrows). $\times 18,000$.

Fig. 21. A section through a small portion of the double delimiting membrane. The osmiophilic layers can be seen on the inside of each unit membrane, and electron-dense material is associated with both sides of the double membrane. $\times 80,000$.

Fig. 22. A longitudinal section through the basal region of a delimiting spore. The archontosome is closely associated with the nuclear beak and the astral-ray microtubules indicate the plane of the delimiting membranes. $\times 32,000$.

Fig. 23. A tangential longitudinal section through part of an ascus taken during the initial stages of spore delimitation. Astral-ray microtubules are closely associated with the invaginating ascus vesicle. $\times \mathrm{I} 8,000$.

\section{Plate 5}

Fig. 24. A longitudinal section through the middle region of an ascus at an early stage of ascospore delimitation. The ascus vesicle invaginates at the points marked by the archontosome-astral-ray complex. $\times 6000$.

Fig. 25. A serial section through the ascus shown in fig. 24. $\times 7500$.

Fig. 26. A longitudinal section through part of an ascus showing four delimited ascospores. Each spore has become orientated so that the archontosome-astral-ray complex lies beneath the nucleus at the base of the spore. $\times 7500$.

Fig. 27. A similar section to that shown in fig. 26 but with biseriate spores. $\times 15,000$.

\section{Plate 6}

Fig. 28. A longitudinal section through a developing ascospore. The archontosome lies at the base of spore and microtubules occur in the cytoplasm between the archontosome and the nucleus. $\times 10,000$. Fig. 29. A micrograph taken at higher magnification of the region shown within the rectangle in fig. 28 . $\times 36,000$. 

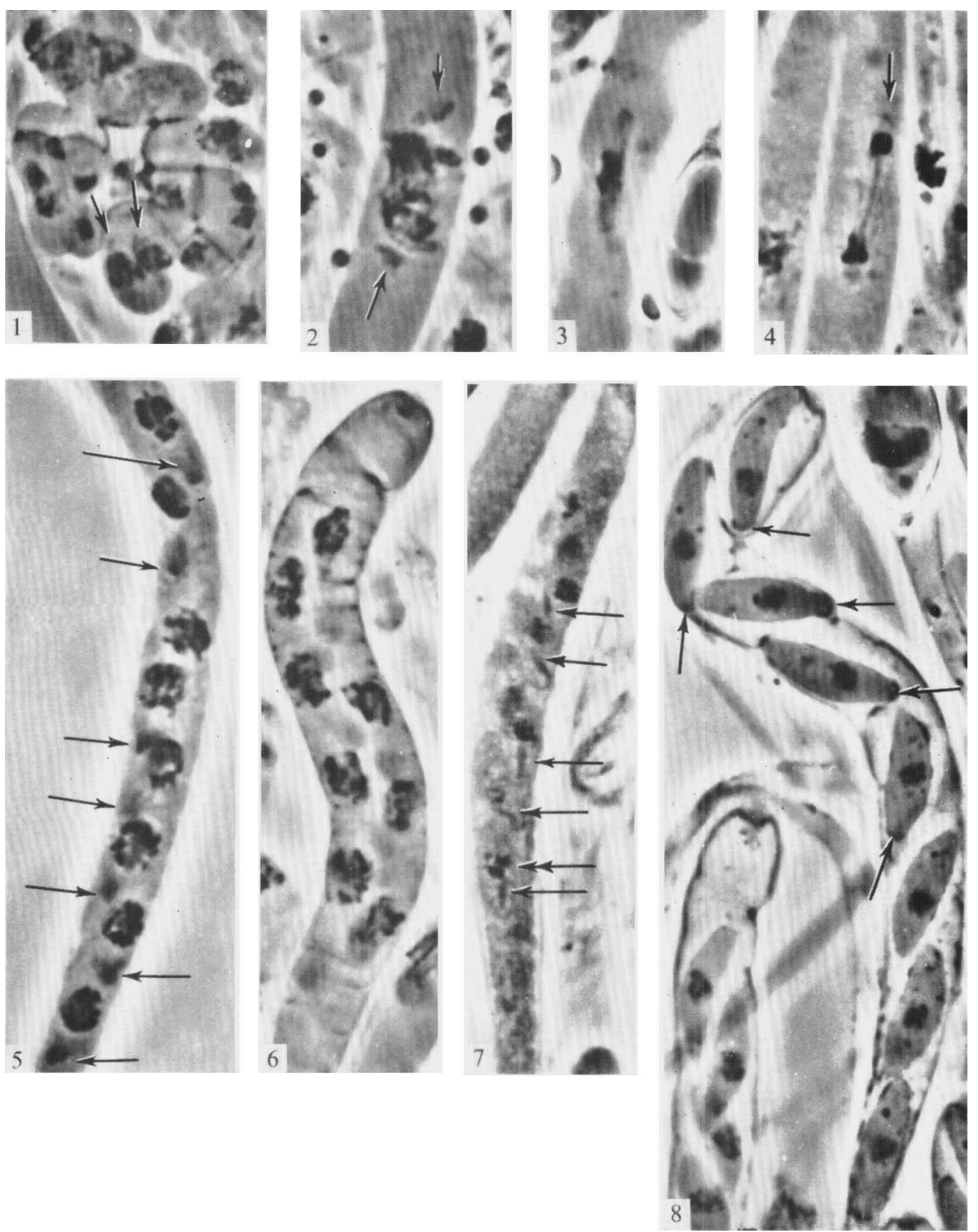
Journal of General Microbiology, Vol. 63, No. 3

Plate 2
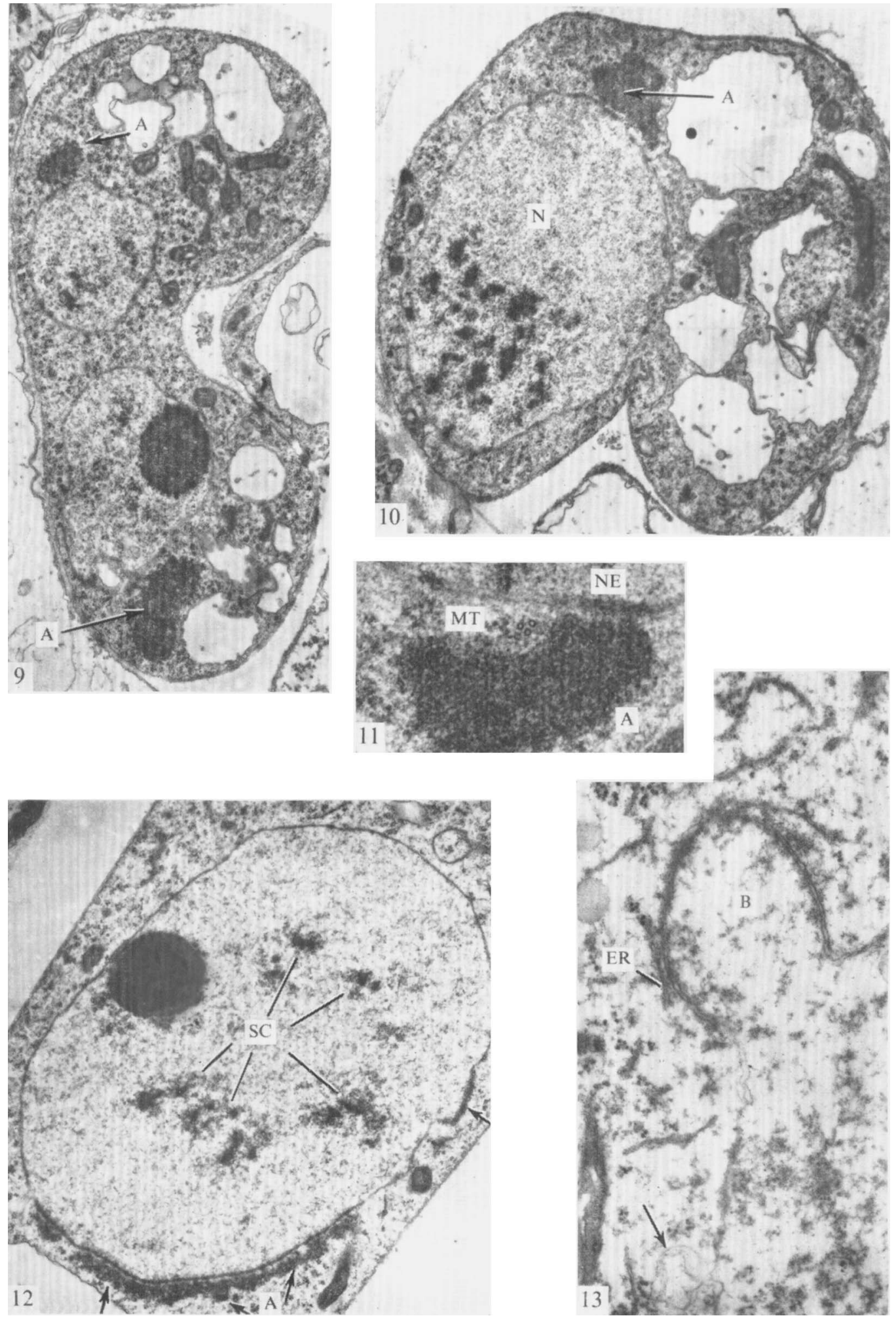

A. BECKETT AND R. M. CRAWFORD 
Journal of General Microbiology, Vol. 63, No. 3
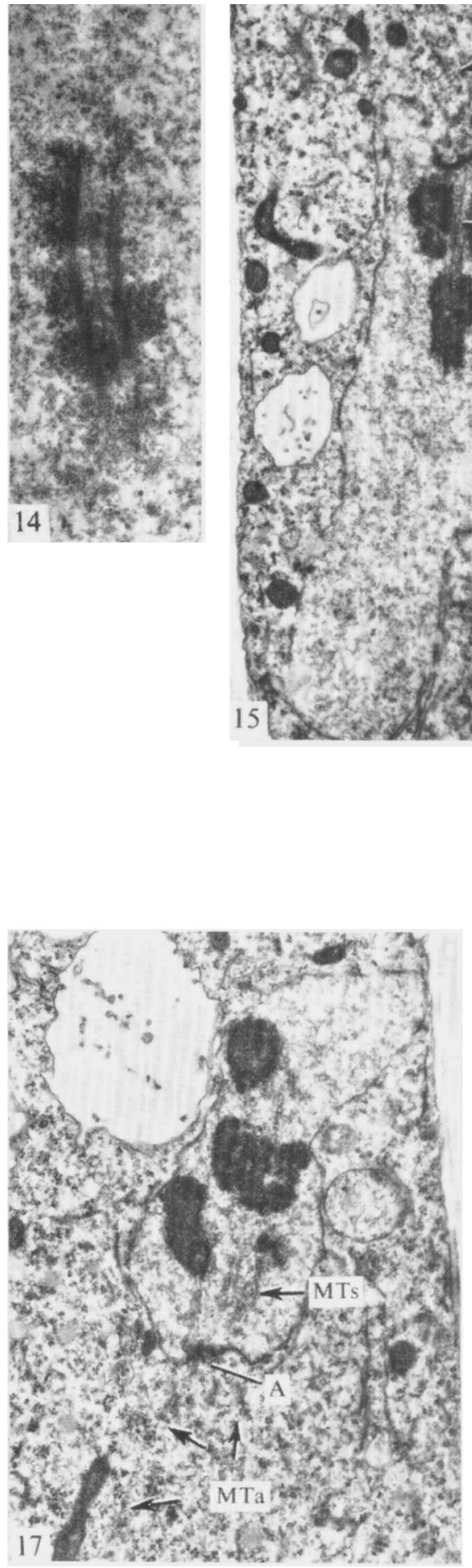

Plate 3

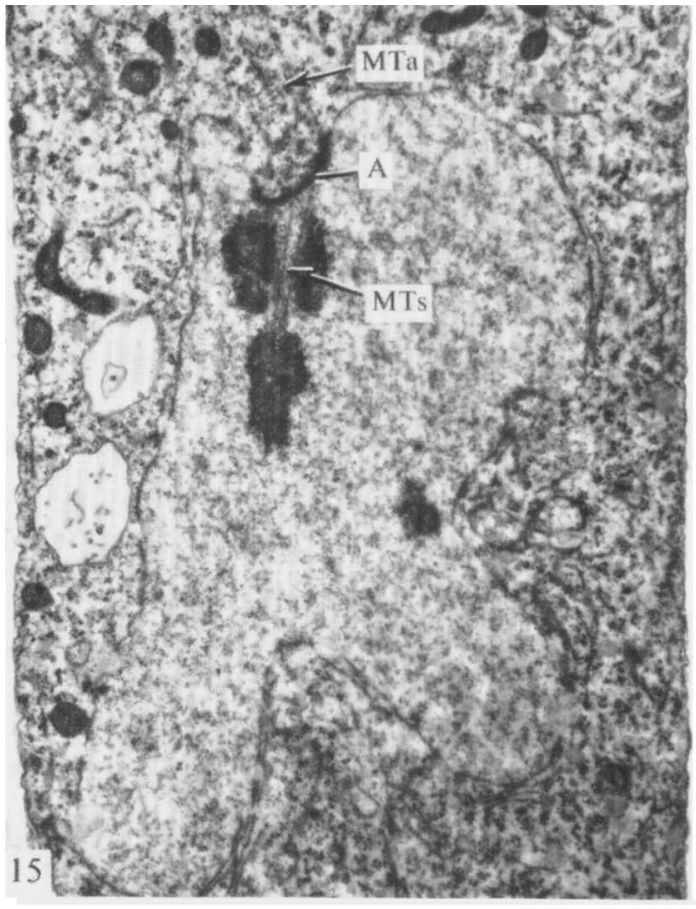

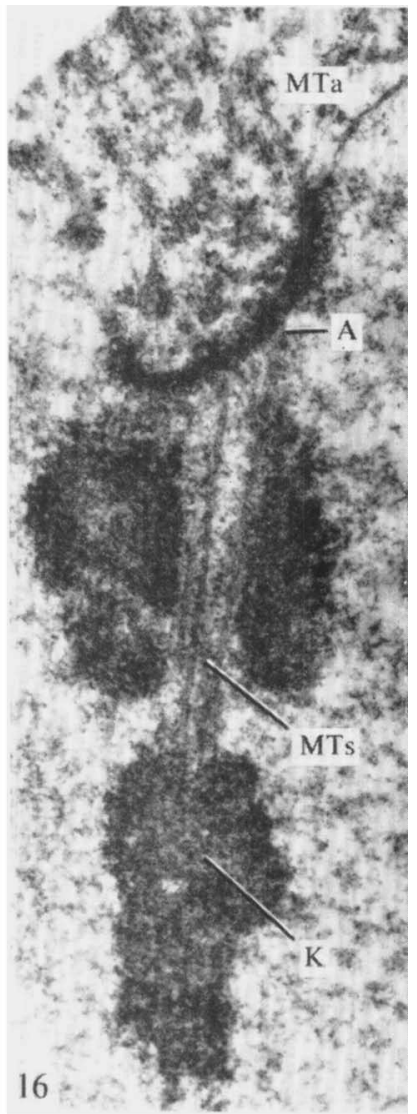

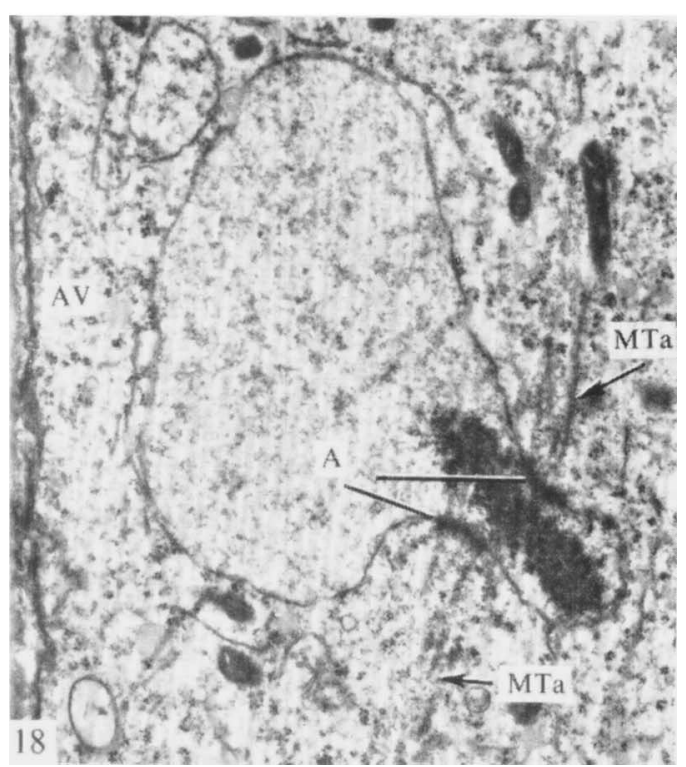

A. BECKET' AND R. M. CRAWFORD 

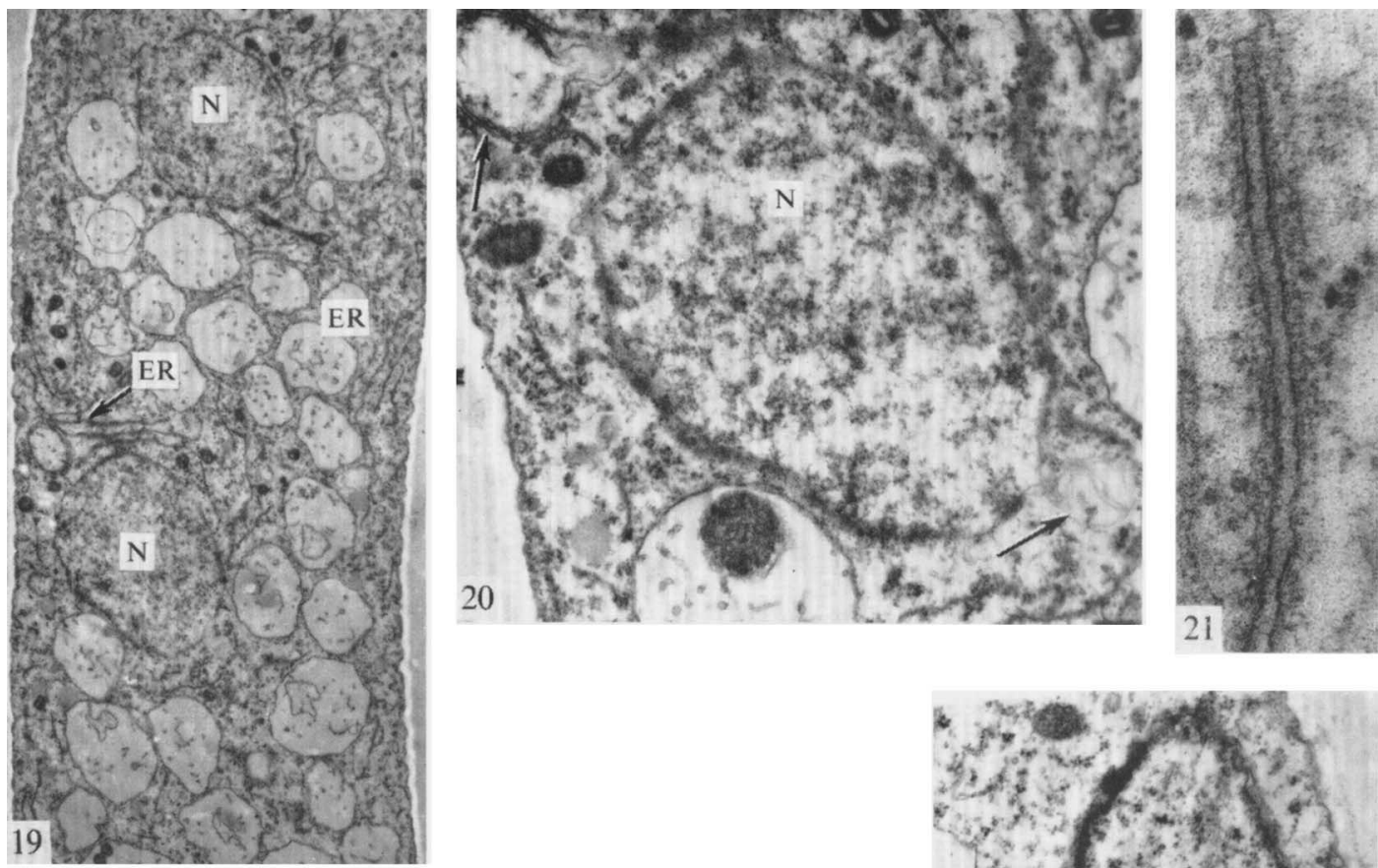
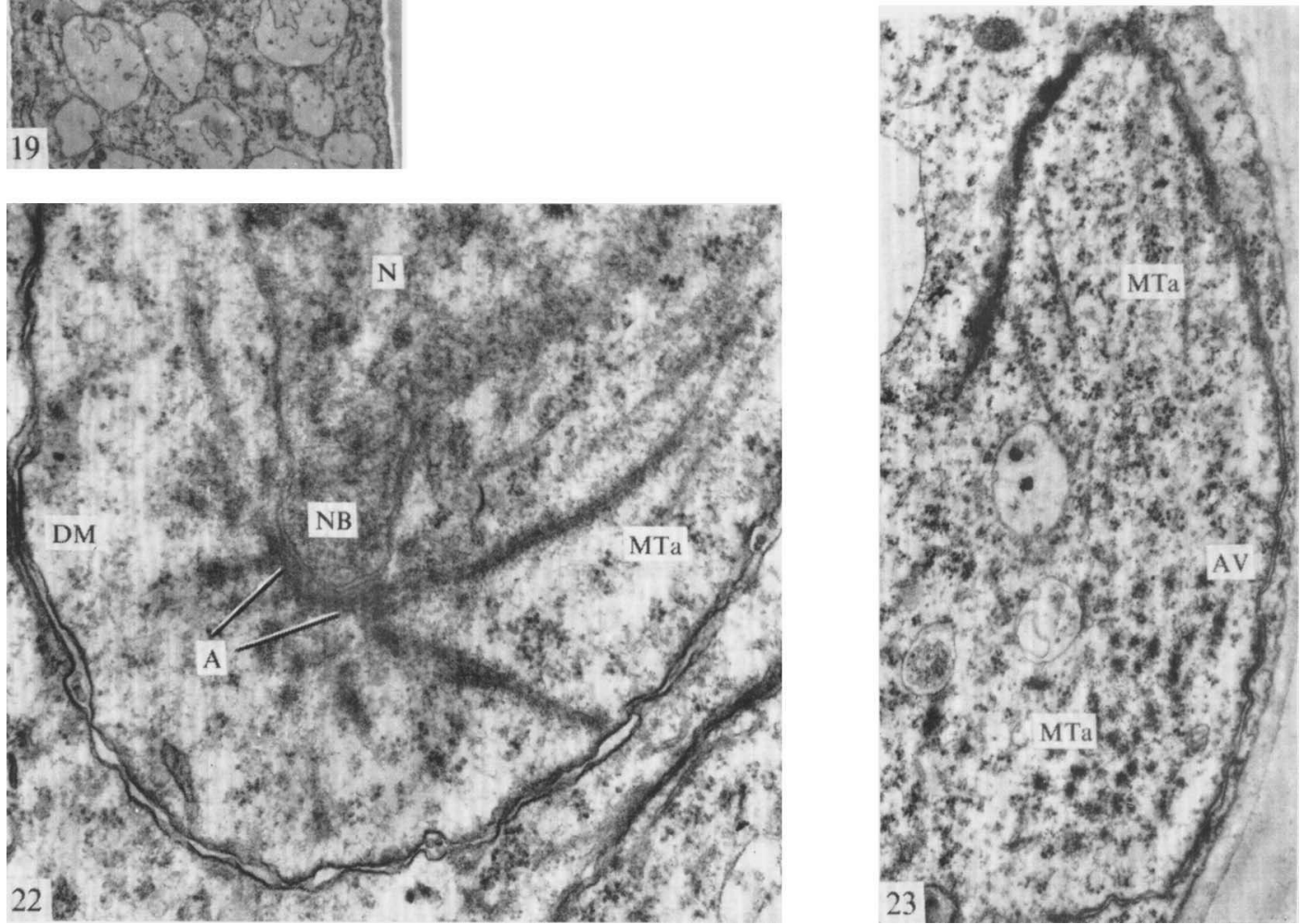

A. BECKETT AND R. M. CRAWFORD 

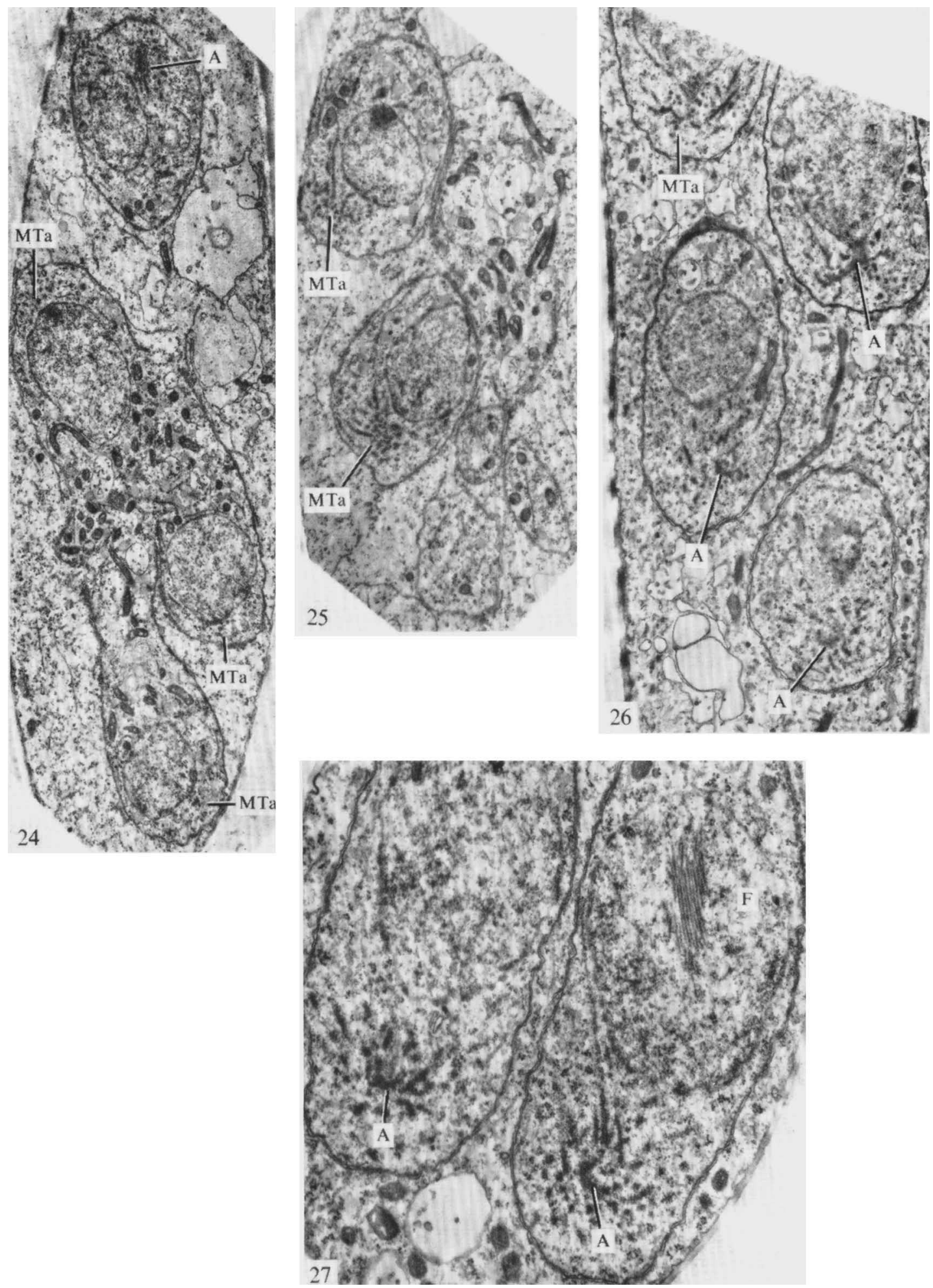

A. BECKETT AND R. M. CRAWFORD 

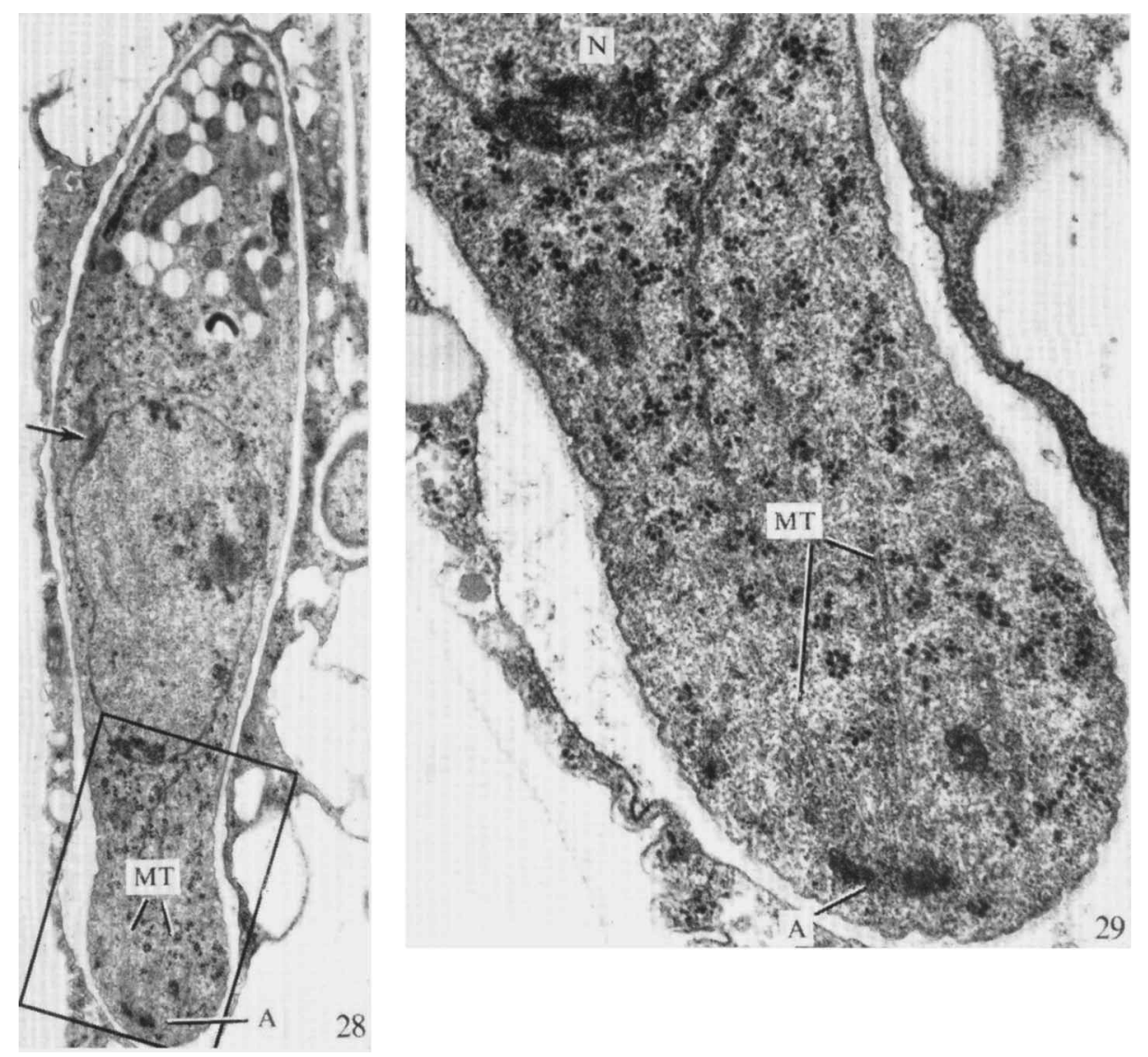